\title{
Fanny Gallot, En découdre. Comment les ouvrières ont révolutionné le travail et la société
}

Paris, La Découverte, 2015

\section{Violaine Girard}

\section{OpenEdition}

\section{Journals}

Édition électronique

URL : http://journals.openedition.org/travailemploi/7316

DOI : 10.4000/travailemploi.7316

ISSN : 1775-416X

Éditeur

DARES - Ministère du Travail

Édition imprimée

Date de publication : 1 octobre 2016

Pagination : 103-105

ISSN : 0224-4365

Référence électronique

Violaine Girard, «Fanny Gallot, En découdre. Comment les ouvrières ont révolutionné le travail et la société », Travail et Emploi [En ligne], 148 | octobre-décembre 2016, mis en ligne le 11 juillet 2019, consulté le 24 septembre 2020. URL : http://journals.openedition.org/travailemploi/7316 ; DOI : https://doi.org/ 10.4000/travailemploi.7316 


\section{Notes DE LECTURE}

\section{En découdre. Comment les ouvrières ont révolutionné le travail et la société}

Fanny Gallot

Paris, La Découverte, 2015, 282 p.

\section{Lu par Violaine Girard"}

Depuis les années 1990, les documentaires consacrés à des ouvrières, mais aussi les films de fiction, les romans ou encore les récits et les témoignages, se sont multipliés à l'occasion notamment des luttes contre les licenciements collectifs. Dans En découdre, l'historienne Fanny Gallot inscrit les expériences vécues par les ouvrières dans un champ plus vaste : comme l'indique le sous-titre : «Comment les ouvrières ont révolutionné le travail et la société », l'ouvrage met en lumière la place et le rôle des ouvrières dans les changements sociaux de l'après-1968 à aujourd'hui. De la « conciliation ${ }^{1}$ » entre maternité et travail salarié féminin au deuil de la vie d'usine face aux fermetures de sites, en passant par les conditions de travail et leurs effets sur la santé, ou les rapports au féminisme et à la syndicalisation, il couvre plusieurs thématiques qui s'articulent autour de douze chapitres.

Si En découdre a pour ambition d'embrasser un ensemble de questions relatives à la condition des ouvrières et, plus généralement, à la dynamique des rapports sociaux dans lesquels celles-ci sont engagées, il ne s'agit cependant pas d'un ouvrage historique de synthèse. L'auteure adopte une démarche originale, faisant dialoguer une enquête de terrain centrée sur deux usines - celle du premier producteur français de lingerie, Chantelle, à Saint-Herblain en Loire-Atlantique, et celle du fabricant d'électroménager Moulinex à Alençon dans l'Orne - avec la restitution des prises de position des principales organisations patronales, syndicales ou féministes et des débats engagés, à différentes périodes, par les instances gouvernementales dédiées à l'emploi et aux conditions de travail des femmes ${ }^{2}$ autour de questions comme le travail de nuit, le congé maternité, la mixité, etc. Le matériau est imposant : outre les vingt-six entretiens qu'elle a elle-même menés avec des ouvrières, F. Gallot mobilise des archives orales (une quarantaine d'entretiens réalisés par d'autres et aujourd'hui conservés

\footnotetext{
* Université de Rouen Normandie.

1. Terme employé dans les années 1970 par les responsables gouvernementaux et patronaux lorsqu'ils discutent des problèmes que pose, de leur point de vue, la généralisation du salariat féminin.

2. Comité du travail féminin durant les années 1970 au sein du ministère du Travail, puis Conseil supérieur de l'égalité professionnelle rattaché au ministère des Droits de la femme.
} 
par des institutions publiques), des sources écrites (archives d'institutions publiques, d'organisations syndicales ou personnelles) ainsi que deux corpus, de récits écrits et de films, permettant d'étudier la parole individuelle et collective d'ouvrières ainsi que les discours et les représentations sociales les concernant. L'ouvrage repose donc sur un matériau empirique riche et inédit, restitué sous forme d'extraits d'entretiens et de documents iconographiques, faisant la part belle au(x) point(s) de vue des ouvrières. On peut toutefois regretter la concision avec laquelle sont évoquées certaines positions syndicales ou patronales, car, de fait, l'ouvrage privilégie les expériences concrètes, collectives et individuelles, des ouvrières.

S'intéressant avant tout à leur(s) façon(s) d'agir sur, et donc de subvertir, au moins en partie, les normes de genre et de classe auxquelles elles sont assujetties, l'auteure emprunte à la philosophe Judith Butler ${ }^{3}$ la notion d'agency (capacité d'agir ${ }^{4}$ ) ainsi que l'importance conférée à la dimension discursive des normes de genre. Elle fait également référence à la sociologue Danièle Kergoat, qui, dans les années 1970 et 1980, propose une analyse « matérielle (matérialiste) $)^{5} »$ de la condition des ouvrières, mettant en évidence l'intrication des rapports sociaux de genre et de classe.

Ces emprunts théoriques sous-tendent notamment les pages sur la « réappropriation » de la «crise de nerfs » (chapitre 4) : affection que les médecins et la hiérarchie usinière considèrent comme «naturellement » féminine, elle devient le déclencheur de nombreuses grèves dans l'après-1968 et témoigne ce faisant de la solidarité collective des ouvrières face aux cadences et aux contraintes corporelles auxquelles elles n'entendent plus se soumettre. Le « droit de cuissage » (chapitre 8) ne suscite pas les mêmes réactions : les stéréotypes de l'ouvrière « fille facile » ou de la « promotion par le corps », repris par certaines ouvrières elles-mêmes, entravent la dénonciation de ces pratiques, même si les résistances individuelles et syndicales permettent la reconnaissance progressive d'un statut de victime, entériné en droit par la notion de harcèlement sexuel en 1992. Le chapitre 9, intitulé «Entre objets et sujets féministes », aborde également l'articulation du genre et de la classe par l'analyse, cette fois, des rapports entre militantes féministes et ouvrières. Les féministes de l'après-mai-juin 1968 portent un vif intérêt aux ouvrières : elles tentent non seulement de les « conscientiser ${ }^{6} »$ mais aussi d'interpréter leurs luttes selon des enjeux qui sont propres aux mouvements révolutionnaires, les groupes féministes étant alors divisés sur la primauté à accorder soit à la domination de classe, soit à celle de genre. F. Gallot insiste, en contrepoint, sur les réticences qu'éprouvent les ouvrières, y compris les militantes syndicales, à se déclarer féministes, car elles perçoivent ces dernières ou bien

3. Butler J. (2005), Trouble dans le genre. Le féminisme et la subversion de l'identité, Paris, La Découverte.

4. Cette notion désigne la capacité qu'ont les individus de modifier les normes sociales qui pèsent sur eux et elles. Elle conduit à porter attention à la façon dont les normes de genre sont incorporées et contraignent les comportements, mais aussi à la manière dont les ouvrières peuvent les redéfinir.

5. Kergoat D. (2012), Se battre, disent-elles..., Paris, La Dispute, p. 12.

6. En tentant de remettre en cause les rôles traditionnels en vigueur dans la sphère privée, ou encore en débattant de contraception. 
comme des gauchistes ou bien comme des femmes issues d'autres catégories sociales. Pourtant, et c'est la thèse que défend l'auteure, les ateliers peuvent être considérés comme des « groupes de femmes à grande échelle ${ }^{7}$ », où s'échangent écoute, conseils et soutiens, au sujet du travail comme de la vie privée. C'est enfin au cours des grèves, menées dans les années 1970 et 1980 pour la dignité au travail, puis, depuis les années 1990, contre les licenciements collectifs, que les ouvrières s'approprient des modes d'action d'ordinaire considérés comme masculins, tels que les occupations de locaux mais aussi les manifestations. Et si ces luttes ont souvent été relayées par la presse de façon paternaliste, comme en témoigne la notoriété des filles de Chantelle au milieu des années 1990, elles sont aussi l'occasion pour ces ouvrières de bouleverser les rôles de femmes et de salariées subalternes qui leur sont imposés : non seulement elles s'affranchissent alors de certaines contraintes domestiques, mais elles battent aussi en brèche la division sexuée du militantisme syndical en usant de modes d'action réservés aux hommes et, enfin, se réapproprient dans certains cas la production en affirmant leurs savoir-faire et leur rôle de conception des produits, mettant ainsi à mal la domination de classe.

La démarche adoptée par l'auteure n'accorde que très peu de place - et c'est un regret - aux différenciations sociales qui traversent le groupe socioprofessionnel des ouvrières : En découdre en livre, de par sa construction, une vision quelque peu homogénéisante, alors que des travaux récents s'attachent aux effets du diplôme, de la qualification, des statuts d'emploi, ou encore des appartenances générationnelles et ethno-raciales sur la cohésion des collectifs de travail ${ }^{8}$ comme, plus largement, sur la structuration interne des classes populaires ${ }^{9}$. Il n'en demeure pas moins que cet ouvrage contribue de façon décisive au renouveau des travaux d'histoire et de sociologie qui, depuis les années 2000, s'intéressent à l'imbrication de la classe et du genre ${ }^{10}$. Tout au long du livre, F. Gallot tient en effet son parti pris de mettre au jour les tentatives de subversion des normes de genre et de classe auxquelles sont assujetties les ouvrières, au fil de décennies d'abord marquées par les luttes ouvrières et l'essor du féminisme, puis par les fermetures d'usines, les luttes et les prises de parole publiques d'une génération d'ouvrières qui a ainsi pu éprouver sa force collective.

7. Expression tirée d'un article coécrit avec Ève Meuret-Campfort (2015), qui approfondit la question du rapport des ouvrières de Chantelle de Saint-Herblain au féminisme et aux normes de genre : « Des ouvrières en lutte dans l'après 1968. Rapports au féminisme et subversions de genre », Politix, n 109, pp. 21-43.

8. Voir par exemple Lomba C. (2010), «Les petites mains des petites entreprises : gestion informelle et fractures ouvrières » Sociologie du travail, vol. $52, \mathrm{n}^{\circ} 4$, pp. 503-520.

9. Amossé T., Chardon O. (2006), «Les travailleurs non qualifiés : une nouvelle classe sociale ? », Économie et statistique, $\mathrm{n}^{\circ}$ 393-394, pp. 203-229.

10. Citons deux références concernant les classes populaires : Meuret-Campfort È. (2014), Des ouvrières en lutte. Mondes populaires et genre du syndicalisme dans un secteur d'emploi "féminin ». Le cas de l'usine Chantelle à Nantes (1966-2005), thèse de doctorat en sociologie, université de Nantes et Avril C. (2014), Les Aides à domicile : un autre monde populaire, Paris, La Dispute. 